\title{
IMPACTO DE LAS S.A.S. EN LA CONSTITUCIÓN DE SOCIEDADES EN COLOMBIA DESDE LA ÓPTICA DEL ANÁLISIS ECONÓMICO DEL DERECHO SOCIETARIO 1
}

\section{Julio Enrique Cortés Riveros ${ }^{2}$ \\ Laura Bernal Maldonado 3}

Artículo Recibido: 4 de abril de 2013 Artículo Revisado: 4 de mayo de 2013 Artículo Aprobado: 4 de mayo de 2013

\section{RESUMEN}

El presente texto está dedicado a examinar el contenido de la Ley 1258 de 2008, como resultado del análisis económico del derecho societario y el impacto en la Constitución de sociedades en Colombia. Este análisis económico del derecho societario busca producir normas dispositivas que permitan reflejar los intereses económicos de los asociados, a partir de 3 premisas fundamentales: Los individuos son racionales, en el sentido en que maximizan su utilidad, tanto en situaciones de mercado como en situaciones de no mercado. Los individuos responden a los incentivos de precios en los mercados y a los incentivos legales, que se pueden asimilar a los precios en las situaciones de no mercado. El sistema jurídico y el impacto del derecho pueden y deben analizarse con base en el criterio de eficiencia.

\footnotetext{
${ }^{1}$ Artículo Avance de Investigación producto tesina de grado. Universidad Militar Nueva Granada.

2 Abogado Universidad Militar Nueva Granada.

${ }^{3}$ Abogada Universidad Militar Nueva Granada.
} 


\title{
PALABRAS CLAVES
}

Tipo societario, análisis económico del derecho, eficiencia, formalización, empresarial, incentivo legal, costos de transacción, empresa unipersonal, agencia.

\section{IMPACT OF S.A.S. IN THE CONSTITUTION OF COMPANIES FROM COLOMBIA OPTICS OF CORPORATE LAW ECONOMIC ANALYSIS}

\begin{abstract}
This paper is devoted to examining the contents of the 1258 Act of 2008 , as a result of the economic analysis of corporate law and the impact on the formation of companies in Colombia. This economic analysis of corporate law seeks to produce operative provisions intended to convey the economic interests of the partners, from 3 premises: Individuals are rational, in the sense that they maximize their utility, both market situations and in situations of no market. Individuals respond to price incentives in markets and legal incentives, which can be assimilated to the prices in non-market situations. The legal system and the impact of law can and must be analyzed based on the criterion of efficiency.
\end{abstract}

KEYWORDS: Type societal, economic analysis of law, efficiency, formalization, business, legal incentives, transaction costs, sole proprietorship, agency. 


\section{IMPACTO DAS S.A.S. NA CONSTITUIÇÃO DE EMPRESAS DA COLÔMBIA ÓTICA DE ANÁLISE ECONÔMICA LEGISLAÇÃO SOCIETÁRIA}

\section{RESUMO}

Este artigo é dedicado a analisar o conteúdo da Lei 1.258 de 2008, como resultado da análise econômica do direito empresarial eo impacto sobre a formação de empresas na Colômbia. Esta análise econômica do direito empresarial visa produzir disposições operacionais destinadas a transmitir os interesses econômicos dos parceiros, a partir de três premissas: Indivíduos são racionais, no sentido de que eles maximizar a sua utilidade, as duas situações de mercado e em situações de há mercado. Os indivíduos respondem aos incentivos de preços nos mercados e incentivos legais, que possam ser equiparados aos preços em situações de não-mercado. O sistema jurídico eo impacto da lei pode e deve ser analisada com base no critério de eficiência.

PALAVRAS-CHAVE: Digite societal análise econômica do direito, a eficiência, a formalização de negócios, incentivos legais, custos de transação, sociedade unipessoal, agência.

\section{INTRODUCCIÓN}

Para quienes han tenido la oportunidad de combinar los estudios de derecho con la actividad empresarial en el sector privado, resulta inquietante, en ocasiones, percibir el derecho, no como una herramienta que permite impulsar el desarrollo, sino como un obstáculo que lo impide. Esta inquietud llevó a los autores de este trabajo a observar cómo la figura de las Sociedades por Acciones Simplificadas (SAS), constituye una herramienta transformadora en el campo del derecho 
comercial en el país, por su flexibilidad y simplicidad, al ir en contravía del régimen societario tradicional.

Esta figura viene teniendo un impacto indudable en el derecho societario nacional, en la medida en que la mayoría de las nuevas personas jurídicas con vocación de lucro en el país han optado por el marco jurídico que les presta las SAS para cobijar su actividad.

Sin embargo, han surgido críticas desde diversos sectores, pues se señala que esta forma societaria - además de romper con los esquemas tradicionales en nuestra legislación - ha sido utilizada para realizar todo tipo de fraudes, particularmente en aspectos tributarios, y para vulnerar los derechos laborales de los trabajadores - en remplazo de la manipulada figura de las Cooperativas de Trabajo Asociado.

Por todo ello, en este trabajo se plantea como problema de investigación la indagación acerca del desarrollo conceptual y empírico de las SAS en el Derecho Colombiano, intentando describir cómo se asumió la figura en nuestra legislación y cómo se ha desarrollado la misma en la práctica del campo societario en Colombia.

Y en esa línea, la pregunta de investigación que guía esta indagación es: ¿EI Análisis Económico de Derecho Societario influenció en la expedición de la Ley 1258 de 2008 y esta a su vez ha impactado en la práctica mercantil, entendida como la creación $y$ formalización de empresas y sociedades comerciales en Colombia? 
Para un trabajo de este nivel y teniendo en cuenta las pretensiones investigativas, el alcance metodológico es principalmente descriptivo y en menor medida explicativo. Es descriptivo porque para esta investigación se cuenta con información acerca del tema principal, el cual ha sido ampliamente debatido desde la promulgación de la ley 1258 de 2008 hasta el día de hoy. Los estudios descriptivos buscan especificar las propiedades, las características y los perfiles importantes de personas, grupos, comunidades o cualquier otro fenómeno que se someta a un análisis. Miden, evalúan o recolectan datos sobre diversos aspectos, dimensiones o componentes del fenómeno a investigar.

Desde el punto de vista científico, describir es recolectar datos. Esto es, seleccionar una serie de cuestiones y medir o recolectar información sobre cada una de ellas, para así (valga la redundancia) describir lo que se investiga. Se cuentan con estadísticas hasta junio de 2012, que demuestran que la promulgación de la ley ha sido de amplia aceptación en el sector empresarial colombiano.

Por otra parte, se considera explicativa porque pretende determinar las causas por la cuales este tipo de sociedad, de reciente creación, ha tenido gran aceptación en los empresarios colombianos, desde la perspectiva del análisis económico del derecho societario.

\section{DEL ANÁLISIS ECONÓMICO DEL DERECHO SOCIETARIO}

Para iniciar, se abordará el estudio del análisis económico del derecho societario, que ha sido una herramienta para el desarrollo del derecho comercial. Desde este punto de vista, se entiende por economía a la ciencia que estudia y ayuda a entender el comportamiento humano; y por Derecho a la ciencia que regula la 
conducta humana. Es decir, cuando se unen estas dos ciencias, podemos llegar a entender cómo el desarrollo jurídico en una sociedad puede llegar a explicar el comportamiento humano.

De acuerdo con lo expresado por Richard Posner (Posner, citado en Reyes, 2012. p. 3):

La economía es la ciencia que se ocupa en estudiar las escogencias racionales de los hombres en un mundo en el que los recursos son limitados. De ahí que el trabajo de los economistas se concentre en identificar las implicaciones que representa el asumir que el ser humano tiende racionalmente a la maximización de su propio interés.

Esta afirmación tiene un importante desarrollo en el estudio del derecho porque los hombres son los sujetos a quienes van dirigidas las normas y quienes, en últimas, deciden qué incentivo escoger de acuerdo al régimen legal existente. Un claro ejemplo es la expedición de la Ley 1258 de 2008, la cual trajo consigo beneficios para los empresarios colombianos, maximizando así sus utilidades, en comparación con otros tipos societarios reglados,

Para abordar el análisis económico del derecho societario, vamos a partir de tres premisas, expresadas por Mauricio Rubio (Rubio citado en Reyes, 2012. p. 21-22):

- Los individuos son racionales, en el sentido en que maximizan su utilidad, tanto en situaciones de mercado como en situaciones de no mercado.

- Los individuos responden a los incentivos de precios en los mercados y a los incentivos legales, que se pueden asimilar a los precios en las situaciones de no mercado.

- El sistema jurídico y el impacto del derecho pueden y deben analizarse con base en el criterio de eficiencia. 
Se considera que el concepto de eficiencia en la promulgación de cualquier norma jurídica, se aplica en aquellas que benefician a un mayor grupo poblacional, teniendo en cuenta costos, procedimientos entre otros, y con las que pueden verse perjudicados algunos grupos minoritarios, sin que se afecten sus derechos fundamentales.

La función del Derecho Societario en la actualidad es la de emitir normas que se ajusten a los intereses económicos de los empresarios, las cuales están dadas en modelos que la misma ley crea, cuya finalidad es la de buscar un equilibrio jurídico entre las partes interesadas. Así las cosas, para los empresarios esto significará menores costos de contratación, porque al adoptar el modelo legal no tendrán que sufragar con gastos propios de la negociación del contrato societario.

\subsection{SOCIEDADES DE CAPITAL DISPERSO Y CONCENTRADO}

Dentro del análisis económico del derecho societario, se devela una problemática de la agencia, es decir, entre los socios y los administradores, la cual cobra relevancia según el sistema económico del que se trate. En la actualidad, existen dos modelos de sociedades de capital: el disperso y el concentrado.

Las de capital disperso son aquellas sociedades que están compuestas por muchos socios y donde existe una clara separación entre propiedad y control. Quienes ostentan la propiedad los socios o accionistas, mientras que quienes ostentan el control son los administradores que dirigen el destino de la empresa. 
Este modelo es propio de países como Estados Unidos y Gran Bretaña. En este tipo de sociedades la legislación se debe preocupar principalmente por regular las relaciones entre los socios y los administradores.

Ahora bien, las sociedades de capital concentrado se caracterizan por una alta concentración de propiedad, en donde existen accionistas mayoritarios y minoritarios, y el control es ejercido por los mayoritarios, unos pocos accionistas que detentan el 50\% o más de las acciones en circulación (Reyes, 2012, p. 39 y p. 43):

Tal es el caso de América Latina, donde el alto nivel de concentración de capital implica que el control sea ejercido con exclusividad por los accionistas mayoritarios. Se ha sostenido en efecto que, como resultado de la estructura de capital en las sociedades latinoamericanas, el aspecto central en los regímenes societarios de esta región es la posible divergencia de intereses entre los accionistas mayoritarios y los minoritarios (...)

(...) Una primera conclusión del Análisis Económico del Derecho Societario en América Latina consiste en la necesidad de tener en cuenta el modelo de capital concentrado que prevalece en la Región, con el propósito de formular políticas legislativas que correspondan a la estructura de capital dominante en los mercados de la Región, por lo que los regímenes jurídicos latinoamericanos podrían enfocarse con mayor propiedad en el problema de agencia que se origina en el conflicto existente entre los accionistas mayoritarios y minoritarios (Reyes, 2012, p. 43).

Con respecto a lo anterior, Colombia presenta en su sistema económico sociedades que en su mayoría corresponden al modelo de sociedad de capital 
concentrado, por lo que la legislación debe estar acorde a este modelo de sociedad, reglando las relaciones entre los socios.

De esta manera es evidente que el legislador aplica las teorías del análisis económico del derecho societario a la Ley 1258 de 2008, regulando así las relaciones entre los accionistas, tal como se lee en los artículos 43 - Abuso del Derecho - y 44 - Atribución de facultades Jurisdiccionales-, que establecen las herramientas para dirimir los conflictos que surgen entre los accionistas.

\subsection{LAS SOCIEDADES Y LOS COSTOS DE TRANSACCIÓN}

La Sociedad como organización de recursos productivos surge en el momento en que el hombre, llámese empresario, se da cuenta que desarrollar un tipo de actividades comerciales en forma individual es más oneroso que hacerlo a través de una Sociedad. Es así como empieza a contratar individuos (empleados) ejerciendo sobre ellos autoridad y dirección, generando la realización de actividades en forma organizada y la distribución de los recursos de manera eficiente, y delegando el poder en un administrador, quien quedará facultado para realizar esta actividad. En conclusión, las sociedades nacen cuando los costos de operar individualmente son superiores a los costos de operar bajo el esquema societario, es decir, cuando se disminuyen los costos de transacción, entendidos estos últimos (Reyes, 2012, p. 48):

Como aquellos en que debe incurrir el empresario para negociar exitosamente y en forma individual con cada uno de sus proveedores de bienes y servicios. A manera de síntesis puedes señalarse que una de las justificaciones que Coase le atribuye a la firma se encuentra, precisamente, en la posibilidad de reducir tales costos. 


\subsection{LA AGENCIA: LOS MANDANTES Y MANDATARIOS}

En primer lugar debemos definir el contrato de Agencia, como aquel mediante el cual un mandante, para nuestro caso en el Análisis Económico del Derecho Societario "Socio", encomienda a un mandatario el desarrollo del objeto social de la compañía, denominado administrador. Este administrador o agente es el encargado de gestionar los recursos sociales y tomar las decisiones necesarias para el buen funcionamiento de la sociedad. Estas decisiones son en beneficio de la sociedad, sin que medien sus intereses particulares. De esto se desprende la necesidad de incurrir en altos costos de fiscalización o no.

\section{APLICACIÓN DEL ANÁLISIS ECONÓMICO DEL DERECHO SOCIETARIO EN LA LEY 1258 DE} 2008

De acuerdo con lo desarrollado en el anterior punto, se considera que la Ley 1258 de 2008 fue producto del análisis económico del derecho societario, por cuanto la ley rompe con la estructura de régimen societario tradicional, convirtiéndose en un régimen más flexible y adoptando algunas características del derecho anglosajón en cuanto a la protección de los inversionistas, tal como lo expresaron Rafael La Porta, Florencio López de Silanes, Andrei Shleifer, y Robert Vishny; más conocidos como LLSV (Reyes, 2012, p. 132):

En un célebre artículo publicado en 1997, los autores sostuvieron que en los sistemas pertenecientes a la órbita del derecho anglosajón ("Common Law") existía un mayor grado de protección para los inversionistas que en los países de tradición Romano-Germánica ("Civil Law”). En esa medida, el estudio antes citado apuntaría hacia la conveniencia de realizar trasplantes jurídicos desde países 
anglosajones hacia naciones de tradición civilista, siempre que tales importaciones normativas se surtan luego de un proceso de adaptación a las condiciones locales de cada país.

Ahora bien, teniendo en cuenta las premisas expresadas por Mauricio Rubio en el capítulo anterior, se entiende que estas se aplican en lo preceptuado por la Ley 1258 de 2008, así:

Cuando se dice que el hombre mediante un proceso racional busca maximizar su utilidad, se considera que un empresario que desee formalizar su empresa o iniciar una nueva actividad mercantil, racionalmente escogería el tipo societario SAS, porque la ley ofrece unos beneficios que le disminuyen sus costos transaccionales en comparación con los tipos societarios tradicionales, tanto en su constitución, como en la ejecución de su actividad. Haciendo la salvedad que en los casos en que el objeto social es especialísimo, este proceso racional estaría limitado por la ley (en la constitución de entidades financieras, en la constitución de sociedades en donde sus acciones van a ser cotizadas en bolsa de valores, entre otras.).

En cuanto a la segunda premisa, en donde se dice que los hombres reaccionan a los incentivos legales, se demostrará cual ha sido el grado de aceptación de los empresarios en Colombia frente a la escogencia del tipo societario SAS. En este estudio se concluye que esta ley es un incentivo para el empresario Colombiano, bien sea para que este se formalice o para que emprenda nuevos negocios.

Conforme a la tercera premisa, en donde se expresa que la regulación normativa debe analizarse bajo la óptica de eficiencia, se deduce que no de otra forma se pudo haber analizado la Ley 1258 de 2008, porque la ley no solo beneficia a los posibles empresarios sino a la estructura económica del país.

Al respecto y para finalizar Reyes Villamizar (Reyes, 2012, p. 134-135) opina: 
La expedición en Colombia de la Ley 1258 de 2008, mediante la cual se introdujo la Sociedad por Acciones Simplificadas (SAS) constituye la comprobación empírica más contundente de la utilización del método del análisis económico en un proceso legislativo (...) La figura ha permitido, así mismo, un incremento sustancial en el número de empresarios que ingresan al sector formal de la economía. Ello se ha traducido en mayores oportunidades de empleo, cumplimiento de normas laborales y fiscales, mayor publicidad ante terceros y crecimiento económico. Y no han sido solamente los microempresarios quienes se han beneficiado de las ventajas de esta novedosa estructura societaria. También los grandes conglomerados Colombianos han acudido a la Sociedad Simplificada para intentar escaparse de los enormes costos de transacción que representaba anteriormente la configuración y el mantenimiento de cualquier grupo de compañías. Al preguntarse cuáles son las razones que justifican el éxito de este prototipo empresarial, debe resaltarse una que es sobresaliente: la amplia libertad contractual que caracteriza a este tipo de compañía, debido al carácter supletorio de las normas contenidas en la Ley que la rigen. Desde luego que, al lado de esta libertad de estipulación, el sistema de la Sociedad Simplificada también es exitoso por su régimen delimitación de responsabilidad, la gran flexibilidad en la estructuración de sus órganos internos y la sencillez del proceso constitutivo.

\section{ANTECEDENTES DE LA LEY 1258 DE 2008 EN COLOMBIA}

Para iniciar con el estudio de las Sociedades por Acciones Simplificadas es primordial analizar los antecedentes nacionales de las Empresas Unipersonales y las Sociedades Unipersonales, las cuales rompen con la teoría clásica del contrato societario, introduciendo una actualización normativa con estas figuras societarias. 


\subsection{LA EMPRESA UNIPERSONAL}

En el año 1995 se expidió la ley 222 que en sus artículos 71 al 81, ingresa al ordenamiento comercial la figura de la "Empresa Unipersonal", según la cual una persona natural o jurídica puede apartar de su patrimonio una parte, formando una persona jurídica diferente y limitando la responsabilidad de la empresa.

En la legislación nacional la Ley 222 de 1995 introduce conceptos manejados también por la Ley 1258 de 2008:

a) Tanto en la Empresa Unipersonal como en las sociedades por acciones simplificadas su constitución puede realizarse por documento privado. $Y$ en los casos en los que el capital que se aporte requiera de transferencia por medio de escritura pública, esta deberá cumplir tal formalidad.

b) En su artículo 71, la Ley 222 de 1995 permite que una persona natural o jurídica destine una parte de su patrimonio para el desarrollo de una actividad de carácter mercantil y en el parágrafo del artículo mencionado establece que si la empresa unipersonal es utilizada en fraude a la ley o en perjuicio de terceros los titulares de la cuota de capital o administradores responderán solidariamente por las obligaciones nacidas de tales actos. Así mismo, en el artículo 42 de la ley 1258 de 2008 se establece igual condición para la desestimación de la personalidad jurídica de las SAS.

c) En los numerales $4^{\circ}$ y $5^{\circ}$ del artículo 72 de la Ley 222 de 1995, dentro de los requisitos de formación se debe establecer: 1) El término de duración si este no fuera indefinido. 2) Una enunciación clara y completa de las actividades principales, a menos que se exprese que la empresa podrá realizar cualquier acto 
lícito de comercio. Lo que nos lleva a compararlo con el artículo 5으 de la ley 1258 de 2008 en su numeral 4ํ donde el contenido del documentos de constitución debe contener el término de duración si este no fuera indefinido. Es decir, para las dos normas se da el mismo precepto. Igualmente, en el artículo 5ํㅡ, numeral 5o de la ley 1258 se debe hacer una enunciación clara y completa de las actividades principales, a menos que se exprese que la sociedad podrá realizar cualquier actividad comercial o civil lícita, es decir que para estas dos normas se da la posibilidad que tanto su termino de duración como su objeto social sean indefinido e indeterminado respectivamente.

\subsection{LA SOCIEDAD UNIPERSONAL}

En el año 2006, la Ley 1014 del 2006 en su artículo 22 - Constitución nuevas empresas - instituye, la nuevas sociedades que se establecen a partir de la vigencia de esta ley, cualquiera que fuere su especie o tipo de conformidad a los establecido en el artículo 20 de la ley 905 del 2004, refiriéndose allí a todas la micro, pequeñas y medianas empresas, que tengan una planta de personal no superior a 10 trabajadores o activos totales por valor inferior a 500 salarios mínimos legales mensuales vigentes, pudiéndose así constituir sociedades unipersonales. Ahora bien, la Ley 1258 de 2008 en su artículo 46 - Vigencia y derogatorias - establece que no se podrán constituir sociedades unipersonales con base en el artículo antes mencionado y por el contrario las ya constituidas deberán transformarse a SAS en un término máximo e improrrogable de 6 meses, desde la fecha de su vigencia.

Por definición un contrato se refiere a un acuerdo de voluntades entre dos o más personas. De acuerdo a lo expuesto por la Corte Constitucional en su Sentencia C-624, se considera que semánticamente no se podría hablar de una sociedad de 
una sola persona, pero dado el desarrollo y la realidad nacional que ha venido en progreso en materia comercial, se hizo necesario crear una sociedad que contemplara a un solo socio, para que este no tuviera que arriesgar todo su patrimonio sino solo una parte de él.

Teniendo en cuenta la confusión que creó la Ley 1014 de 2006, para efectos de la constitución de nuevas sociedades unipersonales, el Gobierno Nacional reglamenta el Artículo 22 de la mencionada ley con el Decreto 4463 del 15 de Diciembre de 2006, en donde establece claramente cuáles son las condiciones y requisitos que debe contener para formarlas.

En este decreto también se observó que existen similitudes con la Ley 1258 del 2008 en cuanto al término de duración, el cual también podrá ser indefinido. En cuanto al objeto, no existe una obligación de enunciar en forma clara y completa las actividades que desarrolle el ente económico, siempre y cuando sean actos lícitos de comercio. Adicionalmente, estas sociedades, podían constituirse por documento privado.

\subsection{EXPOSICIÓN DE MOTIVOS DEL PROYECTO DE LEY SAS}

En el informe de ponencia para primer debate al proyecto de Ley № 241 de 2008 Cámara, 039 de 2007 Senado, publicado en la Gaceta del Congreso 248 el martes 13 de mayo de 2008, se esbozan los antecedentes del proyecto de ley, el cual fue radicado por el Senador Germán Vargas Lleras en la Secretaria del Senado de la República de Colombia, el 25 de Julio de 2007. 
En donde se encuentran la exposición de motivos, los cuales fueron considerados para aprobar dicha ley y a los que se hará mención:

Uno de los debates contemporáneos del derecho privado, se ocupa del estudio del mayor o menor grado de flexibilidad de la legislación que regula a las sociedades. En este sentido, la tendencia actual apunta a simplificar la normatividad en beneficio de un mayor campo de acción a la autonomía de la voluntad privada. Con ello se pretende asegurar la inclusión de la pequeña y mediana empresa en el sector formal de la economía, a través de la consolidación de estructuras societarias menos complejas y, por ende, sujetas a un menor rigorismo jurídico (Congreso de la República, 2008, p. 4).

De acuerdo con lo anterior, este proyecto de ley buscaba la flexibilidad y la simplicidad de la legislación en materia societaria, así como una amplia autonomía a los socios para que estructuren sus empresas conforme a sus necesidades.

En este nuevo panorama, el legislador está llamado a cumplir un papel trascendental en la definición del régimen societario, pues es a él a quien le corresponde establecer un sistema normativo que permita ordenar de manera coherente las reglas de juego que rigen los acuerdos contractuales de los particulares (Congreso de la República, 2008, p. 4).

Así las cosas, como está determinado en el acápite Análisis Económico del Derecho Societario, la función del legislador es la de emitir normas que se ajusten a los intereses económicos de los empresarios, buscando un equilibrio jurídico entre las partes, lo que evidencia que este proyecto de ley responde a los principios generales del Análisis Económico del Derecho Societario. 
En el escenario colombiano, la tipología societaria presenta hoy un fenómeno de rigidez similar al vivido por los franceses a comienzos de 1990. En efecto, el régimen societario sigue sometiéndose a las normas previstas en el Código de Comercio del año 1971 y a las reglas contenidas en la Ley 222 de 1995. Estas disposiciones mantienen una tendencia excesivamente formalista, la cual ha impedido el crecimiento y posicionamiento de las pequeñas y medianas empresas (Congreso de la República, 2008, p. 4).

Es aquí en donde se observa la preocupación del legislador por integrar a las pequeñas y medianas empresas en este tipo societario, ofreciéndoles flexibilidad, simplicidad y autonomía de la voluntad social.

Para este proyecto de ley fueron consultados juristas versados en la materia como Francisco Reyes Villamizar, así como instituciones del orden nacional, la Superintendencia de Sociedades, el Ministerio de Hacienda y Crédito Público, y la Confederación Colombiana de Cámaras de Comercio, quienes demostraron su beneplácito ante el proyecto de ley presentado. Por ello, se transcribe el comentario del Jefe de la Oficina Jurídica de la Superintendencia de Sociedades: "Si este proyecto logra convertirse en ley, se materializaría la tendencia de actualización normativa que se inició en el año 1995 con la ley 222, por virtud de la cual se crea las Empresas Unipersonales de responsabilidad limitada". (Congreso de la República, 2008, p. 4).

Es de aclarar, que la Superintendencia de Sociedades, el Ministerio de Hacienda y Crédito Público como también la Confederación Colombiana de Cámaras de Comercio propusieron realizar unos ajustes al proyecto de ley, los cuales fueron aceptados en su mayoría e integrados al texto definitivo de la norma. 
Con la aprobación de esta iniciativa, el Congreso de la República otorgó una importante herramienta a los ciudadanos, brindándoles una interesante opción en el camino de la competitividad.

Conforme a lo enunciado anteriormente, el Gobierno Nacional sancionó el 5 de Diciembre de 2008 la Ley 1258, promulgándola este mismo día en el Diario Oficial 47.194.

\section{BENEFICIOS DE LA LEY 1258 DE 2008}

Para iniciar el estudio del análisis económico del derecho societario frente a la Ley 1258 de 2008, es necesario establecer cuáles son los beneficios que trae la misma:

\subsection{DE LAS CONSTITUCIÓN DE LAS SOCIEDADES}

En cuanto al documento que protocoliza la constitución de la sociedad, se debe mencionar que, por regla general, todas las sociedades se deben constituir mediante escritura pública; sin embargo, la Ley 1258 de 2008 trae consigo una innovación en este sentido, la cual está determinada en su artículo $5^{\circ}$ donde faculta a los posibles accionistas a realizar el documento de constitución, mediante documento privado, el cual debe ser inscrito en el Registro Mercantil de la Cámara de Comercio del domicilio principal de la sociedad. En todo caso, cuando hubiere un bien que requiera para su transferencia elevarse a escritura pública dicha constitución se hará de la misma manera. 
Esta novedad es uno de los tantos elementos atrayentes que tiene la mencionada ley para los posibles accionistas o inversionistas, dado que simplifica notoriamente los pasos y costos para constituir una compañía en Colombia.

Hasta la Ley 1258 de 2008 se conocían los siguientes tipos societarios: Sociedad en Comandita Simple, Sociedad en Comandita por Acciones, Sociedad Anónima, Sociedad de Responsabilidad Limitada, Sociedad Unipersonal, Sociedad de Hecho y Empresa Unipersonal, que sin ser esta última una sociedad daba la posibilidad a una persona natural para apartar de su patrimonio una porción y con este desarrollar un actividad comercial limitando su responsabilidad al mismo. De acuerdo con la Ley 1258 del 2008 se crea un nuevo tipo societario denominado Sociedad por Acciones Simplificadas (SAS), la cual debe acompañar la razón social que definan sus accionistas.

\subsection{DEL OBJETO SOCIAL}

En la revisión de los objetos sociales es muy común encontrar dentro de los certificados de existencia y representación legal expedidos por las cámaras de comercio en los diferentes tipos societarios, infinidad de actividades que estos pueden desarrollar y que en muchos casos no serán utilizadas por la compañía. El análisis del estudio arrojó que esta circunstancia se debe a que las compañías no quieren limitar su objeto para evitar que en determinado momento la sociedad no tenga la capacidad legal para poder desarrollar esas actividades y se deba recurrir a reformas estatutarias que conllevarían más gastos para la empresa. En la Ley 1258 de 2008, de acuerdo al artículo $5^{\circ}$ en su numeral $4^{\circ}$ - Contenido Documento de Constitución - se posibilita a la empresa no determinar el objeto social en sus estatutos, teniendo siempre la capacidad legal para desarrollar cualquier actividad comercial lícita, sin la necesidad de realizar una reforma estatutaria. Por otra 
parte, se considera que al no limitar el objeto social, la sociedad no se focaliza en unas actividades determinadas generando una falta de especialidad y experticia, lo que conllevaría a que las actividades o servicios que prestan no sean de suficiente calidad.

Por otra parte, la Ley 1258 de 2008 en su artículo 42 - Desestimación de la personalidad jurídica — reza:

Cuando se utilice la sociedad por acciones simplificadas en fraude a la ley o en perjuicio de terceros, los accionistas y los administradores que hubieran realizado, participado o facilitado los actos defraudatorios, responderán solidariamente por las obligaciones nacidas de tales actos y por los perjuicios causados (Reyes, 2009, p. 164).

En lo correspondiente con el Objeto Lícito, las sociedades por acciones simplificadas no están obligadas a determinar el objeto social que desarrollará el ente económico, de acuerdo con lo expresado en el artículo $5^{\circ}-$ Contenido del Documento de Constitución - en su numeral 5ㅜ․

"Una enunciación clara y completa de las actividades principales, a menos que se exprese que la sociedad podrá realizar cualquier actividad comercial o civil, lícita. Si nada se expresa en el acto de constitución se entenderá que la sociedad podrá realizar cualquier actividad lícita".

Así las cosas, teniendo en cuenta que es un requisito de fondo para la validez del contrato social, no necesariamente tiene que ir dentro del texto de constitución en forma expresa, pero independientemente de esta circunstancia cualquiera que 
fuere su actividad comercial, deberá estar acorde "con la ley, el orden público, la moral y las buenas costumbres" (Nossa, 2011, p. 57).

Respecto del objeto social, la Superintendencia de Sociedades en su Oficio 220023132 del 19 de Abril de 2010, reza: "Es permitido que las SAS al diseñar su objeto social hagan una selección de las actividades específicas a las que pretendan dedicarse y a la vez incluyan en la misma cláusula expresiones como las demás actividades licitas, en el entendido que se está dentro de la alternativa del objeto indeterminado que contempla la citada norma y que resulta ser una medida adecuada para aquellos eventos en los que quieran dejarse abiertas posibilidades diferentes de explorar a discreción de los administradores, cuando las circunstancias particulares de la sociedad lo posibiliten."

\subsection{DEL CAPITAL}

El Código de Comercio describe las formas como se debe constituir el capital para las sociedades en general. En las Sociedades con Responsabilidad Limitada el $100 \%$ del aporte debe cancelarse al momento de su constitución, en las Sociedades Anónimas la tercera parte del capital suscrito debe cancelarse en el momento de la constitución y el restante dentro del año siguiente de constitución; en cambio, para las Sociedades por Acciones simplificadas estas reglas no aplican por cuanto el legislador da la libertad a los accionistas para que paguen el capital suscrito dentro de los dos años siguientes a la constitución.

\subsection{DE LAS ACCIONES}

Igualmente, se incluyen las diferentes modalidades de acciones como son: "Las privilegiadas, de pago, con voto múltiple, con dividendo preferencial y sin derecho 
a voto y con dividendo fijo anual" (Reyes, 2009, p. 64). La anterior clasificación no impide que los accionistas puedan crear diversas clases y series de acciones al tenor del artículo 10ำ de la Ley 1258 de 2008 (Revista Superintendencia de Sociedades, 2012, p. web):

\begin{abstract}
(...) Basta reiterar que el legislador confirió total libertad para contemplar diversas clases y series de acciones, incluso distintas de las ya existentes y reguladas antes por el ordenamiento mercantil, libertad que se ve concretada en las posibilidad de fijar y establecer para estas acciones, de origen contractual, los derechos y restricciones que los accionistas en ejercicio de la autonomía de la voluntad y, sin perjuicio de las normas de orden público y las buenas costumbres, consideren apropiados, lo que ha permitido concluir que independientemente de la denominación que pretenda adoptarse, es posible pactar una modalidad de acciones sin derecho a voto, pero sin dividendo preferencial, e igualmente estipular que su naturaleza atípica o especial, como los derechos y las restricciones, se conserven en la medida en que se verifiquen unas condiciones específicas (...).
\end{abstract}

\title{
3.5 DE LOS ÓRGANOS SOCIALES
}

Seguidamente, se hará referencia a los diferentes órganos que componen las sociedades, analizándolos desde el punto de vista de la Ley 1258 de 2008 y realizando comparaciones significativas con otros tipos societarios existentes.

\subsubsection{DE LA ADMINISTRACIÓN}

En cuanto a la administración de la sociedad vemos que la sociedad anónima debe por obligación nombrar junta directiva con sus respectivos suplentes lo cual la hace onerosa y, en ocasiones, puede convertirse en un obstáculo para la toma de decisiones de la empresa. A diferencia de esto, la Ley 1258 de 2008 faculta al representante legal para llevar la administración de la compañía, dando la 
posibilidad de eliminar este órgano de administración que, en algunas sociedades, puede considerarse innecesario.

\subsubsection{DEL REVISOR FISCAL}

Para las sociedades por acciones es obligatorio contar con revisor fiscal, independientemente de sus ingresos y activos; la Ley 43 de 1990 obliga a las Sociedades Limitadas a tener revisor fiscal cuando, el monto de sus ingresos sea superior a 3.000 salarios mínimos legales mensuales vigentes y/o cuando el monto de sus activos a 31 de diciembre del año inmediatamente anterior sea igual o superior a 5.000 salarios mínimos legales mensuales vigentes. Con la entrada de la ley 1258 de 2008 el órgano de la revisoría fiscal no es obligatorio, como se determina en el Artículo 28 de la mencionada ley. Sin embargo, este hecho generó confusión e incertidumbre, dado que en el texto del artículo se expresa que en caso que "(...) por exigencia de la ley se tenga que proveer el cargo de revisor fiscal, la persona que ocupe dicho cargo deberá ser contador público titulado con tarjeta profesional vigente (...)".

\subsubsection{DEL NÚMERO DE ACCIONISTAS}

De acuerdo a lo determinado en el artículo 374 del Código de Comercio las sociedades anónimas no podrán constituirse ni funcionar con menos de cinco accionistas. Conforme a lo establecido en el artículo 17 de la Ley 1258 de 2008, las SAS podrán constituirse y funcionar con un único accionista, es decir, que la asamblea puede ser conformada por un único accionista. Ya la Ley 1014 de 2006 había dado esa posibilidad a las sociedades unipersonales pero con la condición que fuera una sociedad considerada como microempresa. 


\subsection{DEL LUGAR DE REUNIÓN PARA EL DESARROLLO DE LA ASAMBLEA}

Otra de las diferencias del máximo órgano social es el sitio de reunión para el desarrollo de las asambleas. De acuerdo al artículo 426 de Código de Comercio, en las sociedades anónimas "La asamblea se reunirá en el domicilio principal de la sociedad, el día, a la hora y en el lugar indicados en la convocatoria. No obstante, podrá reunirse sin previa citación y en cualquier sitio, cuando estuviere representada la totalidad de las acciones suscritas" (Código de Comercio, 2012, p. 367). A diferencia de esto, la Ley 1258 en su artículo 18 establece que el máximo órgano social, es decir la asamblea podrá reunirse en el domicilio principal o fuera de él, siempre y cuando se cumplan los requisitos de quórum y convocatoria establecidos en los artículos 20 y 22 de la misma ley. Esta situación es beneficiosa en los casos de sociedades en donde pueden existir accionistas de diferentes nacionalidades, incluso en donde la mayoría de los accionistas estén situados en un país extranjero, como por ejemplo, el caso de una compañía en donde la mayoría de sus socios se encuentren ubicados en Chile y la minoría en Colombia. En este caso, si la asamblea se quiere realizar fuera del domicilio principal se podría llevar a cabo siempre y cuando se cumpla con los requisitos exigidos por la ley de quórum y convocatoria, sin importar que exista el quórum universal.

\subsection{DE LAS CONVOCATORIAS}

De otra parte, también se encuentran diferencias entre la convocatoria. Para la sociedad anónima, en el Artículo 424 del Código de Comercio esta se hará según estipulación estatutaria y a falta de estipulación se realizara mediante aviso que se publicará en un diario de circulación del domicilio de la sociedad; para la reuniones en que hayan de aprobarse balances de fin de ejercicio la convocatoria se hará 
cuando menos con 15 días hábiles de anticipación y para los demás casos bastará una antelación de 5 días comunes. En el caso de las SAS para aprobar balances de fin de ejercicio, o aprobar transformaciones, fusiones o escisiones y derecho de inspección, ejercidota convocatoria podrá hacerse durante los 5 días hábiles anteriores a la reunión, siempre y cuando no exista estipulación en contrario en los estatutos y el término sea superior. Para los demás casos este término será de 5 días hábiles. Estos cambios son positivos porque no son tan formalistas y ayudan a la agilidad y eficiencia para la realización de la asamblea. En cuanto a las comunicaciones, estas se adaptaron al entorno tecnológico, teniendo en cuenta que se pueden realizar las convocatorias por cualquier medio escrito, incluyendo el correo electrónico.

\subsection{DEL QUÓRUM}

En cuanto al quórum, la modificación principal que trae consigo la Ley 1258 de 2008, se da en lo referente al concepto de pluralidad, por cuanto en las sociedades anónimas el quórum deliberatorio debe estar conformado por un número plural de socios que representen la mitad más uno de las acciones suscritas. El quórum deliberatorio para las SAS corresponde a un número singular o plural que represente la mitad más uno de las acciones suscritas.

En este aspecto debemos tener como referencia lo expresado por el Doctor Guillermo Cabanellas (Narváez, 1998, p.337):

Quórum se dice en el leguaje parlamentario y en el de otras asambleas para referirse al número de miembros que deben encontrarse presentes para su constitución, deliberación y sobre todo en las votaciones, para eficacia de sus acuerdos. El vocablo comenzó a usarse por los ingleses y ya se aplica incluso en 
lo privado, como en las juntas de accionistas. Se refiere, sin embargo, más bien, a cierta mayoría cualificada en las votaciones, o a un número especial de asistentes (al menos la mitad más uno) para empezar una sesión o junta.

De acuerdo con lo anterior se puede observar que, como la asamblea está compuesta por determinado número de socios o socio como es el caso en las SAS, para que estas reuniones puedan tener poder decisorio deben estar presentes la mayoría de los accionistas y obviamente, el accionista único en caso que la sociedad anónima simplificada este compuesta por una única persona. Narváez, sin embargo, precisa con relación a este punto:

No puede haber asambleas o juntas de socios unipersonales, aunque quien concurra represente todas las partes de interés, cuotas o acciones, en razón a que el órgano supremo de la sociedad es esencialmente colectivo y expresa su voluntad por medio de la mayoría decisoria. Etimológicamente, junta y asamblea significan la reunión de varias personas convocadas para un fin (Narváez, 1998, p.338).

Sin embargo, esta definición fue modificada por la Ley 1258 de 2008 al permitir que las reuniones de asamblea sean válidas así sean efectuadas por una sola persona, colocando como única condición que este accionista represente por lo menos la mitad más uno de las acciones suscritas.

\subsection{DE LA DURACIÓN DE LAS SOCIEDADES}

Ahora bien, en cuanto al término de duración de las sociedades, se hará referencia al artículo 110 del Código de Comercio - Contenido de la escritura de constitución - que en su numeral 9º expresa: "La duración precisa de la sociedad 
y las causales de disolución anticipada de la misma". Esto quiere decir que en todos los estatutos de las sociedades se debe definir exactamente la duración de la empresa, a diferencia de lo establecido en el artículo 5ํ de la Ley 1258 de 2008 - Contenido del documento de constitución - en su numeral 4ํㅜ, que dice: "El término de duración si este no fuera indefinido. Si nada se expresa en el acto de constitución, se entenderá que la sociedad se ha constituido por término indefinido.

Para analizar la duración, se debe tener en cuenta, en palabras de Narváez (Narváez, 1998, p. 426) que:

La expiración del plazo estipulado es una de las causales llamadas normales $u$ ordinarias, común a todos los tipos de sociedad. Su efecto es Erga Omnes pues la disolución se consuma por ministerio de la ley a partir del día en que llega el fin de la duración señalada en los estatutos. Ese hecho es irrevocable e irreversible, y no requiere reconocimiento del órgano máximo de la sociedad, ni ser solemnizado por medio de escritura pública ni inscribirlo en registro alguno.

Esta situación no se daría en las sociedades por acciones simplificadas, en el caso que en sus estatutos no se determine la duración de la sociedad.

La ventaja y el beneficio de constituirse o transformarse en SAS frente a la indefinición en el término de duración y frente a la indefinición de un objeto social es que no se aplicará causal de disolución por vencimiento de término de duración y no tendrá que acudirse a reforma estatutaria de ampliación del objeto social (Maya, 2010, p. 82). 
Adicionalmente, tampoco se tendrá que acudir la reforma estatutaria para la ampliación del término.

\subsection{DE LAS CAUSALES DE DISOLUCIÓN}

Las causales de disolución que trae la ley 1258 de 2008, son:

1. Por vencimiento del término previsto en los estatutos, si lo hubiere, a menos que fuere prorrogado mediante documento inscrito en el Registro mercantil antes de su expiración.

2. Por imposibilidad de desarrollar las actividades previstas en su objeto social.

3. Por la iniciación del trámite de liquidación judicial.

4. Por las causales previstas en los estatutos.

5. Por voluntad de los accionistas adoptada en la asamblea o por decisión del accionista único.

6. Por orden de autoridad competente.

7. Por pérdidas que reduzcan el patrimonio neto de la sociedad por debajo del cincuenta por ciento del capital suscrito.

En el caso previsto en el primer ordinal, la disolución se producirá de pleno derecho a partir de la fecha de expiración del término de duración, sin necesidad de formalidades especiales. En los demás casos, la disolución ocurrirá a partir de la fecha de registro del documento privado o de la ejecutoria del acto que contenga la decisión de autoridad competente (Reyes, 2011, p. 269-270).

En Ley 1258 de 2008 se mantiene el régimen general para la disolución de sociedades, diferenciándose del resto de regímenes societarios en relación con lo 
determinado en el artículo 218 del Código de Comercio en su numeral $3^{\circ}$ que reza: "Por reducción del número de asociados a menos del requerido en la ley para su formación o funcionamiento o por aumento que exceda del límite máximo fijado en la misma ley". Esta circunstancia, como es bien conocido, no se presentaría en las SAS por cuanto su límite mínimo es una persona sin tener un límite máximo.

\subsection{DE LA RESOLUCIÓN DE CONFLICTOS}

Otro punto a tratar es el relativo a la resolución de conflictos al interior de las sociedades, si bien es cierto en el régimen actual de sociedades se pueden establecer clausulas compromisorias para resolver los conflictos al interior de la sociedad, este mecanismo se encuentra limitado por el Artículo 194 del Código de Comercio, que dice: "Las acciones de impugnación previstas en este capítulo se intentarán ante los jueces, aunque se haya pactado clausula compromisoria, y se tramitarán como se dispone en este mismo código y, en su defecto, en la forma prevista en el código de procedimiento civil para los procesos abreviados". En el Artículo 40 de la Ley 1258 de 2008 - Resolución de conflictos societarios - "para resolver los conflictos dentro de esta, se podrá establecer que el medio indicado sea el arbitraje y/o la amigable composición y a falta de estas en todo caso se acudirá a la Superintendencia de Sociedades para que mediante el proceso verbal sumario sea resuelto dicho conflicto". Así las cosas, no se limita a la Superintendencia de Sociedades en ningún tipo de conflictos para la resolución de estos, convirtiéndose así en su juez natural. Es importante resaltar que el legislador buscó con esta norma hacer que la resolución de conflictos fuese más eficiente y que no representara un obstáculo para el desarrollo económico y la inversión extrajera; asimismo, buscó descongestionar los despachos judiciales, asignándole dicho actuar a un grupo de personas expertas en las materias, tal y como lo dice el profesor Luca Enriques "(...) resulta indispensable tener en cuenta 
el denominado 'buen juez de sociedades', cuyo entrenamiento práctico, específico, formación profesional e independencia son necesarios para administrar adecuadamente reglas modernas de derecho de sociedades" (Reyes, 2011, p. 154).

\subsection{DEL ABUSO DEL DERECHO}

Se pueden distinguir tres tipos de abuso del derecho, conforme al artículo 43 de la Ley 1258 de 2008:

\subsubsection{DEL ABUSO DE LAS MAYORÍAS}

El abuso de las mayorías consiste en que los socios mayoritarios aprovechan dicha condición para aprobar decisiones que los beneficiarán a ellos en particular sin tener en cuenta el beneficio común.

En el tipo de sociedades descrito, como queda claro, la mayoría, es decir la voluntad societal, no se define en debates y votaciones que, en ejercicio del concepto de "democracia societaria" puedan llevarse a cabo en la asamblea de accionistas. Ni esta mayoría representa en realidad el interés general de los socios. En estos casos las decisiones se adoptan según los intereses de quien ejerce el control (como la sociedad matriz o la persona jurídica o natural que ostenta - directamente o por interpuesta persona - la mayoría necesaria para tomar la correspondiente decisión) y, en consecuencia tiene la posibilidad de practicar sobre la asamblea general una subordinación activa, esto es, aplicar su poder con el fin de obtener determinados resultados, sin atender a los intereses 0 
derechos del resto de los socios. En este caso es razonable que la ley proteja, especialmente, al accionista minoritario (Corte Constitucional, 2005, p. web).

\subsubsection{DEL ABUSO DE LAS MINORÍAS}

Por otra parte está el abuso de las minorías, ya que si bien es cierto los accionistas minoritarios no tienen el suficiente poder decisorio para lograr un beneficio propio o particular, pueden truncar las decisiones que en un momento dado tome la asamblea en beneficio de la sociedad.

Es evidente que por virtud de la necesaria concurrencia del voto del minoritario en la toma de ciertas decisiones esenciales, debido al establecimiento estatutario de mayorías bastante calificadas, la negativa a aprobar la decisión implica un "Veto" a la operación proyectada y si este resulta necesario para el desarrollo o salvaguarda de los derechos sociales, y si la negativa es injustificada, el socio minoritario deberá resarcir los perjuicios que sufra la sociedad y los consocios, al no poder realizar la operación debatida (...)

(...) El abuso del minoritario constituye un presupuesto negativo. Así como el abuso mayoritario parte del supuesto de la toma de decisiones, el abuso minoritario es de carácter negativo o de bloqueo, en la medida que no hay decisión. Precisamente porque el minoritario se opuso a la misma (Gil y Reyes, 2010, p. 148-149).

\subsubsection{DEL ABUSO PARITARIO}

El abuso paritario se presenta cuando existen dos grupos o personas, cada uno de los cuales representa el $50 \%$ en la toma de decisiones, e igualmente como en el 
minoritario se presenta un bloqueo de decisiones porque se abstienen en la toma de las mismas.

En los tres tipos de abuso del derecho que se refieren, se puede iniciar una acción de nulidad absoluta y/o de indemnización de perjuicios, que como lo expresa el artículo 43 de la Ley 1258 de 2008, se llevará a cabo ante la Superintendencia de Sociedades mediante el proceso verbal sumario.

Un punto sustancial por resaltar es que en materia de SAS definitivamente se rompe el esquema previsto en el artículo 421 del C.P.C. En efecto, dispone el precepto anterior que la demanda de impugnación se dirigirá contra la sociedad. Por el contrario, el artículo 43 de la Ley 1258 parte del presupuesto de que quien debe responder por los perjuicios es el socio que votó a favor de la decisión que se considera abusiva, por lo que la demanda deberá dirigirse contra los socios y no contra la sociedad. Sin embargo, el mismo Artículo 43 permite la acumulación de la demanda de impugnación de decisiones sociales y la demanda de indemnización de perjuicios, al establecer que la acción de indemnización de perjuicios y de declaratoria de nulidad absoluta de la decisión se tramitará ante la Superintendencia de Sociedades. En caso de acumularse ambas pretensiones, serán demandados la sociedad y los socios, aunque la indemnización de perjuicios solo recaiga en estos últimos (Gil y Reyes, 2010, p. 154).

\subsection{LOS BENEFICIOS DE LAS SAS FRENTE AL ANÁLISIS ECONÓMICO DEL DERECHO SOCIETARIO}

De acuerdo a lo visto anteriormente, La Ley 1258 de 2008 trae múltiples beneficios para quienes quieran constituir una sociedad bajo este tipo societario y sin lugar a 
dudas el análisis económico del derecho societario tiene una influencia preponderante en el articulado final de la Ley.

Dentro de los beneficios de la Ley 1258 de 2008 y a la luz del análisis económico del derecho societario, se considera que algunos de estos, son maximizadores de la utilidad dentro del proceso racional que realicen los individuos, como por ejemplo:

a) En la constitución de la sociedad, la cual se puede realizar por documento privado sin incurrir en costos que generaría constituirla mediante escritura pública.

b) En el objeto social hay lugar a una posible una disminución de los costos de transacción, en la medida que no se debe realizar reformas estatutarias al no tener un objeto social determinado.

c) La no obligatoriedad de contar con una junta directiva, generaría una disminución en los costos de transacción, por cuanto no se incurrían en los honorarios de los miembros de junta y sus respectivos suplentes.

d) Siendo este tipo societario una sociedad por acciones, no tiene la obligatoriedad de contar con revisor fiscal, situación que genera menos costos de transacción para la empresa.

e) La no obligatoriedad de realizar la asamblea en el domicilio principal, dependiendo de la circunstancia de la sociedad y de los socios, podría disminuir los costos de transacción.

f) En cuanto a las convocatorias, ya no es obligatorio publicar el aviso en un diario de circulación del domicilio principal de la sociedad, hecho que genera una disminución en los costos de transacción.

g) Respecto a la duración es evidente que implica una disminución en sus costos de transacción, por cuanto la compañía no debe someterse a una reforma estatutaria para ampliar la duración. 
h) Con relación a las causales de disolución, las SAS tienen la ventaja de que en caso de disminuirse o aumentarse el número de socios, esta situación nunca conllevaría a una causal de disolución. Situación que evitaría que el empresario incurra en costos de transacción como lo sería el tener que transformarse a un nuevo tipo societario o el enervamiento de la causal de disolución.

Por otra parte, la norma trae unos incentivos legales que bajo la óptica del análisis económico del derecho societario, buscan influenciar el comportamiento de las personas. Esta influencia corresponde primero, a que las personas que estén desarrollando una actividad económica se formalicen y segundo, que se formalicen bajo el tipo societario SAS, como por ejemplo:

a) Respecto del capital, el legislador da la libertad a los accionistas para pagar el capital suscrito dentro de los dos años siguientes a la fecha de su constitución. Este es un incentivo para los accionistas, por cuanto no necesariamente en el momento de su constitución deben aportar una suma de dinero determinada.

b) En cuanto a las acciones, el legislador da una amplia libertad a los accionistas para la creación de diferentes tipos, de acuerdo a las necesidades de cada sociedad.

c) Con relación a la pluralidad de accionistas, la norma admite que se forme una sociedad de una sola persona, lo que permite que un individuo pueda formar su propia sociedad sin recurrir a terceros que le sirvan como figuras decorativas para poder constituirla.

d) El hecho de eliminar la pluralidad en el quórum, puede generar una mayor agilidad en la toma de decisiones y puede ser un incentivo para un accionista, el cual tenga la mitad más uno de las acciones suscritas en este tipo societario.

e) La norma le da la opción a los accionistas para que puedan solucionar los conflictos surgidos dentro de la sociedad, primero por el arbitramento o amigable composición o, a falta de estos, los conocerá la superintendencia de sociedades, 
lo que implica que la resolución de conflictos sea un incentivo para los accionistas por cuanto podrán resolver sus diferencias de manera pronta y eficiente.

f) Desde el punto de vista del abuso del derecho los socios minoritarios tendrán como incentivo legal que sus derechos se vean salvaguardados frente a los derechos de los socios mayoritarios, en virtud de los mecanismos de protección que ofrece la norma.

\section{LA COMBINACIÓN PERFECTA: LEY 1429 DE 2010 FRENTE A LA LEY 1258 DE 2008}

Dentro del estudio de las Sociedades por Acciones Simplificadas es importante hacer referencia al proyecto de ley No. 057 de 2010 Cámara, 187 de 2010, Senado, el cual pretende incentivar la formalización de pequeñas empresas a través de la progresividad en el pago del impuesto a la renta, de los aportes parafiscales y del registro mercantil, así como la generación del primer empleo para los jóvenes menores de 27 años que durante los tres años de anteriores a la vinculación laboral han obtenido el título de educación superior (Congreso de la República de Colombia, 2010, p. web). La Ley No.1429 fue promulgada por el Gobierno Nacional el 29 de Diciembre de 2010 (Congreso de la República de Colombia, 2010, p. web).

Considerando que la Ley 1258 de 2008 antecede a la de ley de formalización empresarial, es lógico pensar que los empresarios, para acogerse a los beneficios de esta última, se constituirán bajo el tipo societario SAS.

\subsection{DE LA INFORMALIDAD}

De acuerdo a los análisis presentados por el Ministerio de Comercio, Industria y Turismo de la República de Colombia el 26 de Octubre de 2011 en el Foro de 
Formalización Empresarial y Laboral realizado en Medellín, se determina que la informalidad que se presenta en Colombia, afecta tres grandes grupos como son:

1. El laboral, porque es conocido que los empleados que laboran en empresas informales no cuentan con los beneficios que la misma ley les otorga y que muchas veces para su reconocimiento deben acudir al aparato judicial existente en el país. Estos trabajadores no están cubiertos por el sistema de seguridad social, incluso no reciben como ingreso un salario mínimo, como tampoco tienen acceso a las cajas de compensación.

2. Otro de los aspectos que afecta la informalidad es el sector empresarial, el cual genera muchos riesgos, empezando por al que están expuestos los dueños de dichas sociedades con la totalidad de su patrimonio, que en un momento dado puede desaparecer; por traer un ejemplo el hecho de que uno de los colaboradores fallezca como consecuencia de un accidente de trabajo y no esté afiliado al sistema general de riesgos profesionales, trae consigo una carga económica que fácilmente acabaría con un patrimonio familiar. $\mathrm{Si}$ el causante tenía como ingreso un salario mínimo, el capital necesario para cubrir una pensión de sobrevivientes es de cerca de 850 millones de pesos.

3. El otro aspecto que analiza el Ministerio de Comercio es la informalidad del producto, puesto que el bien o servicio que se suministra puede estar por fuera de los estándares requeridos para su comercialización, trayendo riesgos incluso para la salud humana, dependiendo de los bienes o servicios que se presten.

A juicio del Ministerio de Comercio, Industria y Turismo, algunas causas de la informalidad son: la carga tributaria que deben soportar las empresas, como son los impuestos de Renta, IVA, de patrimonio (a nivel nacional) y el impuesto de 
industria y comercio (a nivel distrital), así como los costos laborales. Por ejemplo, la contratación de una persona con salario mínimo (\$566.700) y un subsidio de transporte de (\$67.800), implica un costo real para el empresario de (\$929.184) mensualmente, teniendo en cuenta los aportes de salud, pensión, riesgos profesionales, caja de compensación, cesantías, prima legal y vacaciones. Otra de las causas de la informalidad empresarial es la cantidad de trámites que se deben surtir para la misma formalización: conseguir alguien que sirva de guía, la escritura pública, la inscripción en el RUT, la inscripción en impuestos distritales, los libros de contabilidad y su registro, además de ,muchos otros requisitos, dependiendo de la actividad,

\subsection{BENEFICIOS DE LA LEY DE FORMALIZACIÓN EMPRESARIAL}

De acuerdo con estos antecedentes una de las estrategias para la formalización empresarial y generación de empleo es la promulgación y puesta en marcha de la ley 1429 de 2010, por lo que se describirán los beneficios que trae la misma.

Inicialmente se debe aclarar que los beneficios aplican para las pequeñas empresas, que por definición de la misma ley son las empresas “(...) cuyo personal no sea superior a 50 trabajadores y cuyos activos totales no superen los 5.000 salarios mínimos mensuales legales vigentes" (Congreso de la República de Colombia, 2010, p. web).

El impuesto de renta se pagará un $0 \%$ los dos primeros años, del impuesto a cargo. El tercer año se pagará el 25\% del impuesto a cargo, el cuarto año se pagará el 50\% del impuesto a cargo, el quinto año se pagará el 75\% del impuesto a cargo y a partir del sexto año se pagará el 100\% del impuesto a cargo. Los parafiscales se pagarán un $0 \%$ del total de aportes para los dos primeros años, 
para el tercer año se pagará el $25 \%$ de los aportes, para el cuarto año se pagará el $50 \%$ de los aportes, para el quinto año se pagará el $75 \%$ del valor de los aportes y del sexto año en adelante el $100 \%$ de los aportes. Así mismo, para el valor de la matrícula mercantil se pagará el $0 \%$ del total de la tarifa establecida para la obtención de la misma, el 50\% para su renovación en el segundo año, el $75 \%$ para su renovación en el tercer año y a partir del cuarto año el $100 \%$ de la correspondiente tarifa. (Congreso de la República de Colombia, 2010, p. web)

En conclusión, teniendo en cuenta todos estos beneficios que el Gobierno otorga para la formalización de empresas y la facilidad de crear Sociedades por Acciones simplificadas, la gran mayoría que se formalizarán o se han formalizado son empresas bajo el tipo societario Sociedades por Acciones Simplificadas.

\section{IMPACTO DE LA LEY 1258 DE 2008 EN COLOMBIA A JUNIO DE 2012}

Los gráficos que se encontrarán a continuación fueron realizados con base en las estadísticas suministradas por la Confederación Colombiana de Cámaras de Comercio, la cual es un organismo de carácter Nacional que coordina y brinda asistencia en el desarrollo de sus funciones a las Cámaras de Comercio Colombianas. Confecámaras trabaja en propiciar la competitividad y el desarrollo regional a través del fortalecimiento de las Cámaras de Comercio como instituciones y la representación proactiva de la red ante el Estado para promover la competitividad de las regiones Colombianas en temas de formalización, emprendimiento e innovación empresarial (Confecámaras, 2012, p. web).

La información presentada en las gráficas que se expondrán en este punto, corresponde a los años 2009 a 30 de Junio de 2012. En donde se muestra la participación de los diferentes tipos societarios en los periodos mencionados. 
Es de aclarar que la gráfica 5.3 que corresponde a la Ley de Formalización Empresarial fue realizada con base en las estadísticas del año 2011 suministradas por la Cámara de Comercio de Bogotá, es decir que el impacto de dicha ley solo se evidencia en la ciudad de Bogotá.

\subsection{Gráfica No.1: Distribución tipos societarios en Colombia al 30 de Junio de 2012}

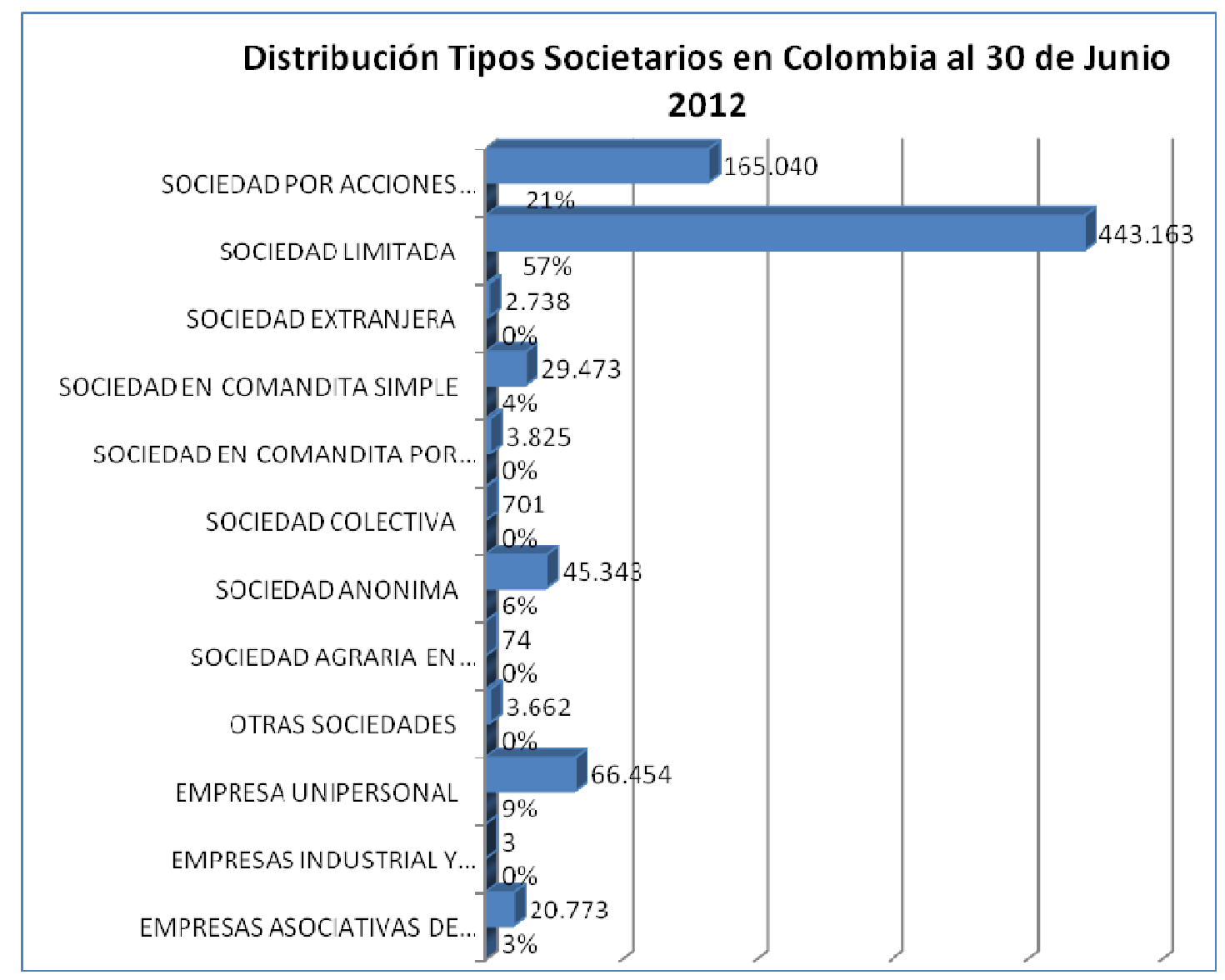

Fuente: Confecámaras 
En la Gráfica No.1 se puede observar el impacto que ha generado la expedición de la Ley 1258 de 2008, que con tan solo 3 años y 6 meses de vigencia, se ha posicionado como el segundo tipo societario más utilizado por los Colombianos para formalizar sus empresas, correspondiendo al $21 \%$ de la totalidad de empresas constituidas en Colombia. Este es el resultado de los beneficios consagrados en la norma, en donde se demuestra que los accionistas han tratado de maximizar su utilidad y han respondido positivamente a los incentivos que la ley trae consigo.

5.2. Gráfica No. 2: Evolución de las Sociedades por Acciones Simplificadas Matriculadas en Colombia durante el año 2009 


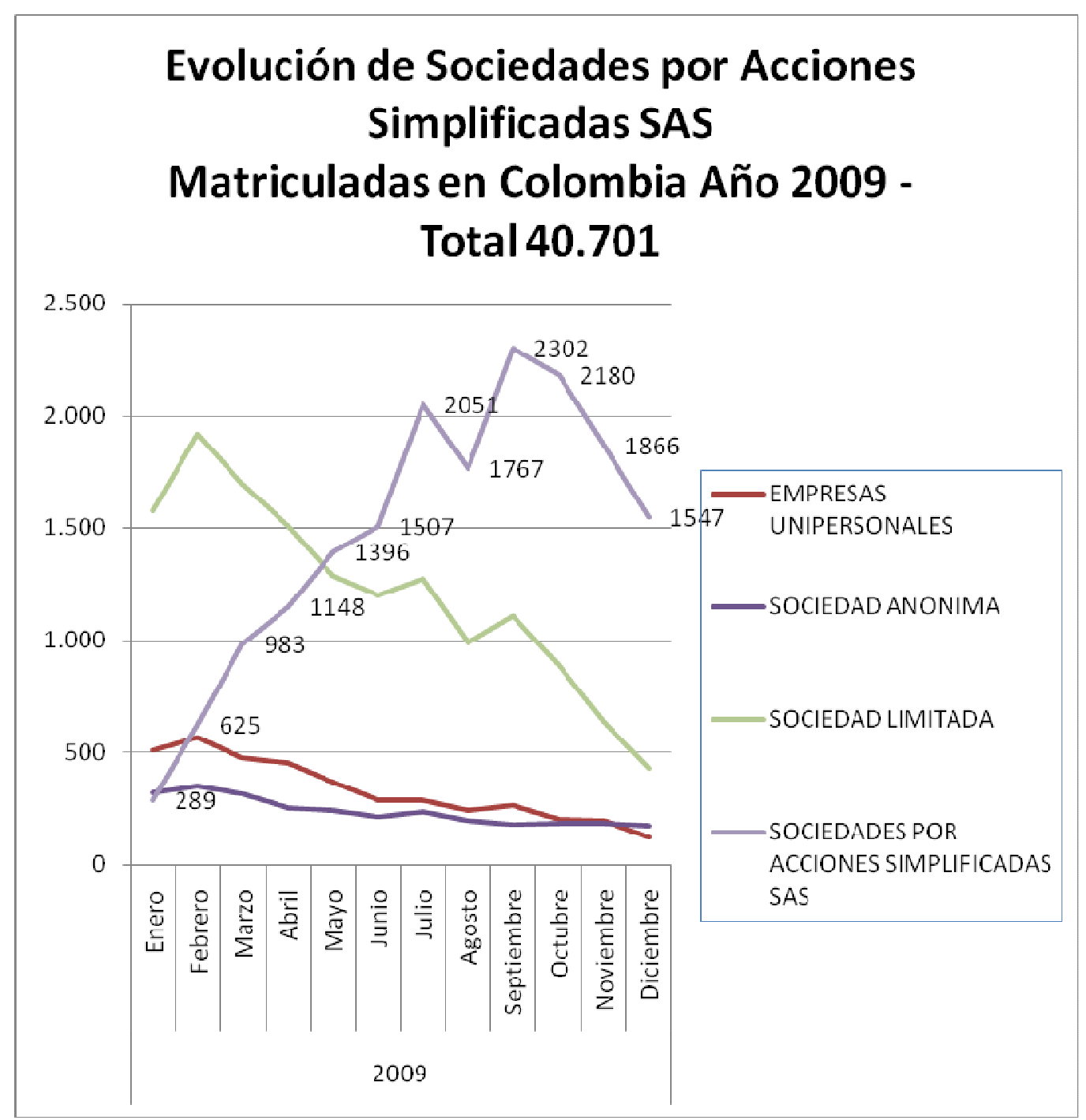

Fuente: Confecámaras

De acuerdo a la Gráfica No.2, se demuestra que en el primer año de vigencia de la Ley 1258 de 2008, ocurrió un fenómeno en el medio empresarial colombiano nunca antes visto y fue como consecuencia de la expedición de la ley.

El tipo societario tradicional, como lo es la sociedad limitada, empezó a constituirse en menor medida y más aún tipos societarios como la empresa 
unipersonal y la sociedad anónima, mermaron su constitución hasta el punto de ocupar el tercero y cuarto lugar respectivamente en constitución de sociedades en el país para el año 2009.

Nótese que en el mes de abril del año 2009, la constitución de los tipos societarios sociedad por acciones simplificadas y sociedad limitada se equiparan y que a partir de este momento, la sociedad por acciones simplificadas asciende considerablemente, mientras que las sociedades limitadas tienden al descenso en la escala de constitución, Demostrándose así el grado de aceptación de los empresarios colombianos frente al incentivo de la ley.

5.3. Gráfica No. 3 Sociedades Beneficiarias de la Ley 1429 de 2010 registradas en la Cámara de Comercio de Bogotá en el año 2011

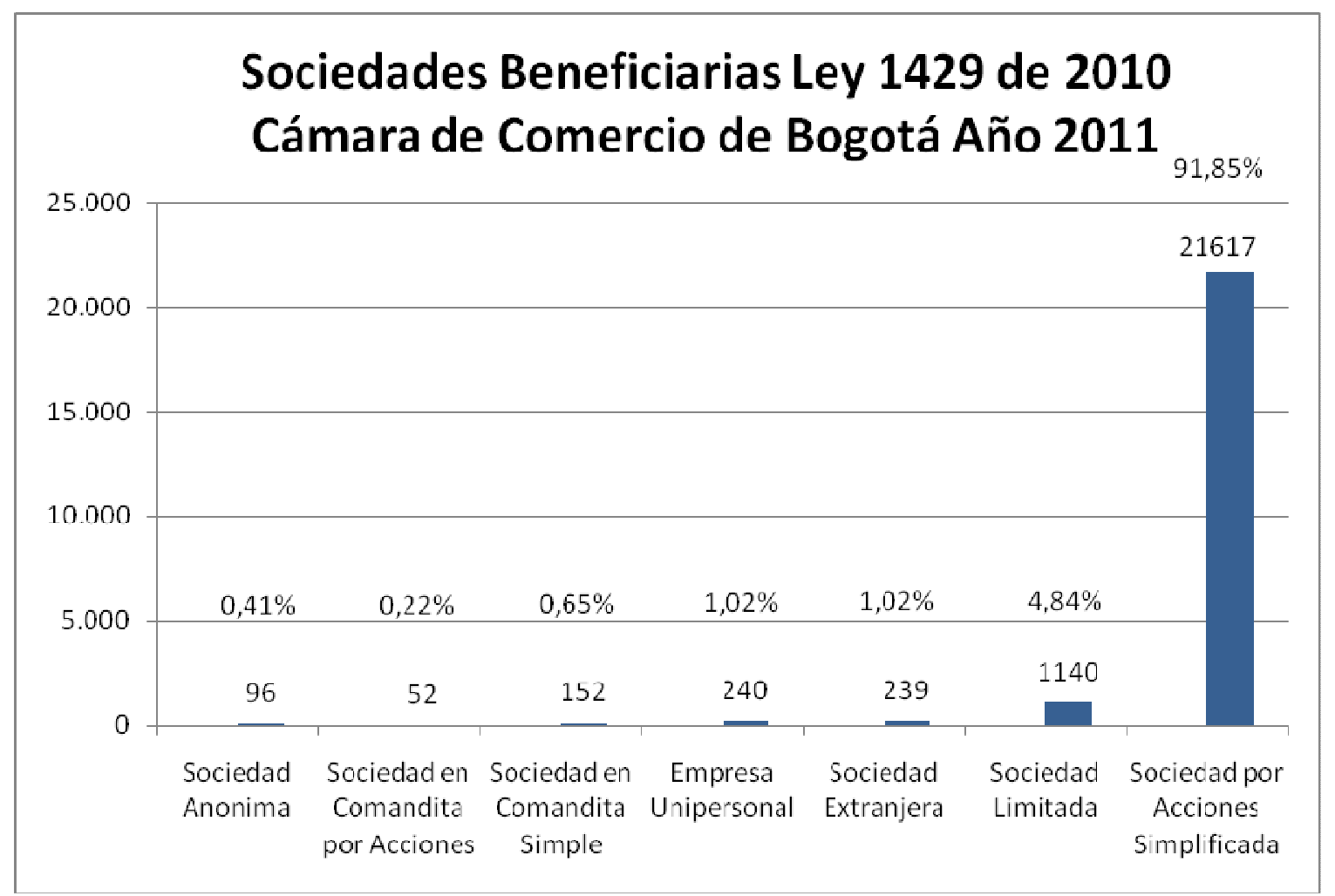


Fuente: Cámara de Comercio de Bogotá

De acuerdo al análisis que se realiza de la Gráfica No.3 en la ciudad de Bogotá y para el año 2011, como era de esperarse los empresarios y comerciantes colombianos que decidieron acogerse bajo la ley 1429 de 2010 optaron por matricularse con el tipo societario SAS dados sus beneficios y ventajas. Tan solo en el año 2011 en Bogotá se matricularon 21.617 SAS que corresponden al $91.85 \%$ del total de las sociedades constituidas bajo los beneficios de la ley 1429 de 2010.

\section{CONCLUSIONES}

La expedición de la Ley 1258 de 2008, la cual introdujo en el ordenamiento jurídico Colombiano la Sociedad por Acciones Simplificadas, es una clara muestra de la utilización del análisis económico del derecho societario en la creación de una norma jurídica, teniendo en cuenta la flexibilidad y simplicidad, la cual está beneficiando a todos los accionistas que se constituyeron bajo este tipo societario, tal y como fue la intención del legislador al momento de presentar el proyecto de ley. Adicionalmente, tuvo sus orígenes en las necesidades que el medio empresarial exigía en Colombia, al considerar que los tipos societarios existentes eran arcaicos con estructuras rígidas y no correspondían a la libertad contractual que los empresarios colombianos exigían en su momento, como tampoco a la situación actual del país.

Las Sociedades por Acciones Simplificadas sí generaron un impacto en el medio empresarial colombiano y lo demuestran las estadísticas contenidas en este trabajo. Para el año 2009, con tan solo un año de vigencia de la Ley 1258 de 2008, la sociedad por acciones simplificada fue el tipo societario escogido por los 
empresarios para constituir sus sociedades comerciales, lo que implicó que en su primer año hubiese desplazado a los tipos societarios tradicionales como se muestra en el Gráfico No.2. De las sociedades matriculadas en el año 2009, que corresponden a 40.701, el 43\% corresponde a Sociedades por Acciones Simplificadas, mientras que el 36\% corresponde a Sociedades Limitadas y un 10\% a Empresas Unipersonales. Para el año 2012, a Junio 30, en Colombia se encontraban constituidas 165.040 sociedades por acciones simplificadas ocupando el segundo lugar de la totalidad de las sociedades constituidas, que representaban el $21 \%$, posicionándose así en el mercado con tan solo 3 años y medio de vigencia de la ley.

Los beneficios del articulado de la Ley 1258 de 2008, fueron suficiente razón para que los empresarios que querían formalizar su negocio escogieran este tipo societario para hacerlo, en comparación con la onerosidad de los otros tipos societarios tradicionales.

En el año 2010, el Gobierno Nacional promulga la Ley 1429, la cual incentiva la creación de empresas mediante los beneficios otorgados por la misma, como son: tributarios, parafiscales y de registro mercantil. Dentro del análisis realizado a las estadísticas de la Cámara de Comercio de Bogotá para el año 2011, el 91.85\% que corresponden a 21.617 empresas beneficiarias de esta ley, se constituyeron bajo el tipo societario Sociedad por Acciones Simplificadas, lo cual evidencia la aceptación del tipo societario que se ha estudiado en la ciudad de Bogotá. En razón, de los beneficios de la Ley 1258 de 2008 más los beneficios de la Ley 1429 de 2010, era de esperarse y así es, que los nuevos empresarios se acogieran a estas normas y así disminuir los costos de transacción a su cargo. 
De otra parte, en las últimas semanas se conoció por parte de la Organización de Estados Americanos (OEA) su intención de adoptar íntegramente la Ley 1258 de 2008 como proyecto de ley modelo al interior de los Estados miembros, con el fin de modernizar el régimen societario de América Latina. Igualmente, al interior de la Naciones Unidas en la Comisión para el Derecho Mercantil Internacional se ha organizado un conversatorio acerca de la Sociedad por Acciones simplificadas basada en el modelo Colombiano. Esto significa para Colombia un respaldo a este modelo legislativo por lo que no tendría sentido, teniendo en cuenta este apoyo internacional, que el Gobierno realizará las ya anunciadas reformas estructurales a la norma.

\section{BIBLIOGRAFÍA}

Ámbito Jurídico. (2012, 20 de agosto al 02 de septiembre). La SAS Colombiana es la base de leyes modelo propuesta en la OEA y Uncitral. Núm. 352. 20.

Barrero Buitrago, Álvaro. (2011). Manual para el Establecimiento de Sociedades. Bogotá: Librería Ediciones del Profesional.

Becdach Fierro, Andrés. (2004). Empresas Unipersonales de Responsabilidad Limitada en el Ecuador: Análisis de su Funcionalidad Teórico y Práctica. Recuperado el 24 de octubre de 2012, de http://repositorio.usfq.edu.ec/bitstream/23000/337/1/84601.pdf. 24 Mayo de 2004.

Betancurt Assmus, Andrés. (2012). En defensa de las SAS. Recuperado el 19 de Mayo de 2012, de http://sectorial.co/index.php?option=com content\&view=article\&id=282:en-defensa-de-lasas\&catid=40:informes-especiales\&ltemid $=208$.

Cámara de Comercio de Bogotá y Banco Interamericano de Desarrollo (BID). (2010). Impacto de la Informalidad Empresarial en el Crecimiento y la Productividad. Memorias Foro Experiencias en Formalización Empresarial y Laboral en Ciudades de América Latina. Recuperado el 28 de Julio de 2012, 
http://camara.ccb.org.co/documentos/5755 foro experiencias en formalizacion empresarial y la boral parte 1.pdf.

Colombia. (1991). Constitución Política. Bogotá: Leyer.

Colombia. (2012). Código de Comercio. Bogotá: Legis.

Confecámaras. (2012). Qué es Confecámaras. Recuperado el 27 de octubre de 2012, de http://www.confecamaras.org.co/.

Congreso de la República. (1970). Decreto 2163 de 1970. Recuperado el 14 de Febrero de 2012, de ftp://ftp.camara.gov.co/camara/basedoc/decreto/1970/decreto 2163 1970a.html

Congreso de la República. (2008, 26 de febrero). Proyecto de Ley 039 de 2007 Senado. Gaceta del Congreso 60. 61-62.

Congreso de la República. (2008, 13 de Mayo). Informe de Ponencia para Primer Debate al Proyecto de Ley Número 241 de 2008 Cámara, 039 de 2007 Senado.

Gaceta del Congreso 248. 4.

Congreso Nacional de la República. (2008, 5 de Diciembre). Ley 1258 del 5 de Diciembre de 2008, por medio de la cual se crea la Sociedad por Acciones Simplificada. Diario Oficial 47.194.

Congreso de la República. (2008). Ponencia para Primer Debate al Proyecto de Ley Número 057 de 2010 Cámara, 187 de 2010 Senado. Recuperado el 26 de octubre de 2012, de http://servoaspr.imprenta.gov.co:7778/gacetap/gaceta.mostrar documento?p tipo=37\&p numero= 057\&p consec=27451.

Congreso de la República. (2010). Ley 1429 del 29 de Diciembre de 2010, por medio de la cual se expide la Ley de Formalización y Generación de Empleo. Recuperado el 24 de mayo de 2012, de http://www.secretariasenado.gov.co/senado/basedoc/ley/2010/ley 1429 2010.html 
Congreso de la República. (2010). Ley 1430 de Diciembre de 2010, por medio de la cual se dicta normas tributarias de control y para competitividad. Recuperado el 24 de mayo de 2012, de http://www.secretariasenado.gov.co/senado/basedoc/ley/2010/ley 1430 2010.html

Cooter, Robert y Ulen, Thomas. (1998). Derecho y Economía. México: Fondo de Cultura Económica.

Corbetta, Piergiorgio. (2007). Metodología y Técnicas de Investigación Social. Madrid: Mc Graw Hill.

Corredor Alejo, Jesús Orlando. (2011). Análisis y Comentarios a la Ley de Reforma Tributaria, Ley de Formalización Empresarial y Generación de Empleo, e Impuestos de Emergencia Invernal. Bogotá: Hache: Tributar Asesores SAS.

Corte Constitucional. (2005). Sentencia C-707 de 2005. Recuperado el 19 de mayo de 2012, de http://www.secretariasenado.gov.co/senado/basedoc/cc sc nf/2005/c-707 2005.html.

Corte Constitucional. (2010). Sentencia C-014 de 2010. Recuperado el 19 de mayo de 2012, de http://www.secretariasenado.gov.co/senado/basedoc/cc_sc_nf/2010/c-014_1910.html.

Gil Echeverri, Jorge Hernán y Reyes Villamizar, Francisco (coord.). (2010). Estudios sobre la Sociedad por acciones simplificada. Abuso decisorio en el régimen de las SAS. Bogotá: Universidad Externado de Colombia.

Gómez Sierra, Francisco. Constitución Política Anotada. Bogotá: Leyer. 2006

Hernández Sampieri, Roberto. (2007). Fundamentos de Metodología de la Investigación. Madrid: Mc Graw Hill.

La República. (2012). Colombia se estanca en competitividad. Recuperado el 27 de octubre de 2012, de http://www.larepublica.com.co/competitividad/colombia-se-estanca-encompetitividad 23885. 
Maya Maya, Gabriel Ricardo. (2010). Razones y Beneficios para Constituirse o Transformarse en SAS. Medellín: Biblioteca Jurídica Diké.

Mendoza Ramírez, Álvaro y Reyes Villamizar, Francisco (coord.). (2010). Estudios sobre la sociedad por acciones simplificada. Antecedentes Nacionales de la Ley 1258 de 2008. Bogotá: Universidad Externado de Colombia.

Ministerio de Comercio, Industria y Turismo República De Colombia. (2011). Estrategia para la Formalización. Recuperado el 30 de Mayo de 2012, de http://www.camaramed.org.co:81/mcc/sites/default/files/doc digital/anexos/2011/Nov/2.estrategiapa ralaformalizacionMCIT.pdf.

Monroy Cabra, Marco Gerardo. (1998). Introducción al Derecho. Bogotá: Temis.

Morales De Setien Ravina, Carlos. (2011). Análisis Económico del Derecho. Bogotá: Siglo del Hombre Editores: Universidad de Los Andes: Pontificia Universidad Javeriana - Instituto Pensar.

Narváez García, José Ignacio. (1998). Teoría General de las Sociedades. Bogotá: Legis.

Narváez García, José Ignacio. (2002). Derecho Mercantil Colombiano: Tipos de Sociedad. Bogotá: Legis.

Nossa Peña, Lisandro. (2011). De Las Sociedades Comerciales. Bogotá: Universidad Santo Tomás.

Posner A., Richard. (2011). Análisis Económico del Derecho. Bogotá: Siglo del Hombre Editores: Universidad de los Andes: Pontificia Universidad Javeriana, Instituto Pensar.

Presidencia de la República. (1970, 16 de Diciembre). Decreto número 2163 del 9 de Noviembre de 1970, por medio del cual se oficializa el servicio de notariado. Diario Oficial 33.233.

Rincón Ríos, Jarvey. (2011). Sociedades Comerciales: De las Formas Asociativas sin Ánimo de Lucro, a las Formas Societarias Tradicionales, E.U y S.A.S. Santiago de Cali: Biblioteca Jurídica Dike. 
Reyes Villamizar, Francisco. (1996). Reforma al Régimen de Sociedades y Concursos. Bogotá: Cámara de Comercio de Bogotá.

Reyes Villamizar, Francisco. (2009). La Sociedad por Acciones Simplificada. Bogotá: Legis.

Reyes Villamizar, Francisco. (2011). La Sociedad por Acciones Simplificada. Bogotá: Legis.

Reyes Villamizar, Francisco. (2012). Análisis Económico del Derecho Societario. Bogotá: Pontificia Universidad Javeriana, Grupo Bancolombia, Grupo Editorial Ibáñez.

Rubio, Mauricio. (2007). Economía Jurídica. Bogotá: Ediciones de la Universidad Externado de Colombia.

Ruíz López, Hernando. (2010). Empresas Colombianas: Actualidad y Perspectivas II. Bogotá: Superintendencia de Sociedades.

Vanegas Torres, Gustavo. (2004). Guía para la Elaboración de Proyectos de Investigación en Derecho. Bogotá: Universidad Libre, Centro de Investigaciones Socio Jurídicas. 